\title{
Planejamento de um Serious game Voltado para Saúde Bucal em Bebês
}

\author{
Alana M. de Morais ${ }^{1}$ \\ Liliane dos S. Machado ${ }^{1}$ \\ Ana Maria Gondim Valença ${ }^{2}$
}

Resumo: Serious games são jogos computacionais que tem como principal característica ensinar aspectos específicos de disciplinas ou treinar habilidades operacionais e comportamentais. Esses jogos unem a diversão dos videogames convencionais com processos decisórios do jogador, sistemas de avaliação e planejamento pedagógico a fim de criar um ambiente de aprendizado envolvente. Essas características ampliam as possibilidades de atuação desses jogos e, por isso, chamam a atenção de outras áreas do conhecimento. Nesse sentido, merecem destaque os projetos em parceria com os profissionais da Saúde que tem contribuído de forma significativa no treinamento, educação e informação de profissionais e pacientes. Neste contexto da multidisciplinaridade nos serious games que este artigo apresenta uma metodologia utilizada no planejamento de um jogo voltado para mães, com intuito de ensinar e informar sobre conceitos relacionados à saúde bucal de bebês. Esta concepção foi baseada na avaliação da Abordagem de Comunicação, que se refere a uma série de informações importantes na

${ }^{1}$ LabTEVE/UFPB, Federal University of Paraíba.

Zip Code: 00000-000. João Pessoa-PB, Brazil.

alana_labteve@yahoo.com.br, lilianeddi.ufpb.br

${ }^{2}$ Department of Social and Clinical Dentistry/UFPB. Federal University of Paraíba.

Zip Code: 00000-000. João Pessoa- PB, Brazil.

anavaleterra.com.br 
construção do jogo como conceituação artística, tipo de narrativa, roteiro, enredo, ambiente, interatividade, gênero do jogo e jogabilidade. Para obter as impressões do público-alvo e estabelecer a melhor Abordagem de Comunicação para o jogo foram construídos dois protótipos com Abordagens de Comunicação distintas, uma com enredo Formal e outra com enredo Lúdico, e um formulário para coletar estas impressões. Os dados obtidos foram analisados descritivamente, mediante valores absolutos e percentuais. Ao final da etapa de testes, o estudo mostrou que a abordagem Lúdica e a abordagem Formal motivam de forma semelhante. Entretanto, no aspecto envolvimento, a abordagem Lúdica se destacou da Formal. Em geral, os usuários sentiram-se mais estimulados a finalizar o protótipo Lúdico e consideraram que as mensagens e o cenário permitem um fácil entendimento nos protótipos explorados.

Abstract: Serious games are computer games with specific purposes, such as: training, learning, valuation etc. These games connect the fun of common videogames with features like decision making, assessment systems and educational planning in order to create an engaging learning environment. So these aspects create endless possibilities of use in those games and attract attention from other areas of knowledge. Therefore, the design process becomes increasingly complex and involves multidisciplinary teams. This paper presents an interdisciplinary study conducted to define an approach based on communication for the development of a serious game for dentistry, specifically oral health in babies. We intend to evaluate what is the best approach to be applied to the script of the game in order to define the good way to present the content. In this paper, the "communication approach" term joins features such as: game play, game design, interaction, narrative, story genre and script. In this project, it was necessary to evaluate which 
communication approach is appropriate in a serious game aimed at mothers. We developed two prototypes to test different communication approaches. At the end of the test stage, the mothers answered a form to evaluate the most appropriate communication approach. The data were analyzed through absolute and percentage values. Finally we decided adopt a Playful Approach, because the mothers felt more encouraged to finalize this application compare to Formal Approach. 


\section{Introdução}

Os jogos computacionais evoluíram ao longo dos anos e alcançaram a maioria dos espaços na sociedade. Diversos fatores contribuem para tal fato, um deles é a atuação dos mesmos em diversas áreas do conhecimento com objetivos específicos, por exemplo: comercial, político, treinamento, educacional e entretenimento [1]. De acordo com Thompson et al. [2], estas ferramentas são mediadores capazes de proporcionar ao usuário imersão, atenção, conhecimento funcional, autocontrole, motivação, estimular a tomada de decisão e os sentimentos de competência e autonomia. Diante deste contex to e baseado nos aspectos positivos destes jogos nos processos de ensino e de aprendizagem, [3] definiu estas ferramentas como uma importante tendência social. Esta posição de destaque dos jogos com relação às outras mídias digitais pode ser atribuída ao equilíbrio entre desafio e envolvimento do jogador durante a interação [4].

Diante das possibilidades de atuação dos jogos, estes podem ser classificados de maneiras distintas considerando os seguintes elementos: roteiro, faixa etária do público-alvo, proposta, gênero, interatividade ou objetivo [5]. Nestas perspectivas, se destaca a classificação baseada nos objetivos dos jogos que resultam nos seguintes subgrupos: jogos casuais (casual games), jogos publicitários (advergames) e serious games [6]. Jogos casuais são aqueles cujo enfoque está centrado na diversão do jogador, os publicitários têm o intuito de promover uma marca, campanha ou produto e, por fim, os serious games têm como característica principal ensinar aspectos específicos de disciplinas ou treinar habilidades operacionais e comportamentais. Não é adequado usar a terminologia jogos sérios para esta última modalidade de jogo, pois tal tradução não abrange a totalidade do significado empreendido pelo termo em inglês.

Todo serious game necessita de um planejamento pedagógico antecedendo e subsidiando a etapa de desenvolvimento. Nesta fase é definido a temática explorada e como apresentá-la ao jogador. Depois disto, é necessário definir aspectos técnicos como o roteiro, conceituação artística (game design), jogabilidade (gameplay) e definição da interface [1], características importantes na construção do Game Bible do projeto. Outro elemento que aumenta a complexidade dos serious games é a participação de várias ciências no projeto para alcançar, de forma colaborativa, um objetivo específico em comum [7]. A equipe multidisciplinar envolvida é quem norteia e determina todas as etapas de construção nesta modalidade de jogo.

Na construção de serious games específicos para Saúde, a presença e participação dos profissionais da área é essencial para que tais ferramentas tenham validade e possam ser amplamente utilizadas pelos usuários finais. Tal parceria tem contribuído, de forma significativa, no treinamento, educação e informação destes profissionais e de pacientes, uma vez que estas ferramentas estimulam e motivam o aprendizado dos jogadores. Diversos fatores são considerados relevantes à expansão destas aplicações: as dificuldades encontradas na obtenção de materiais, validação de produtos e treinamento de pessoal, bem como a necessidade de novas abordagens para reabilitação e ensino de hábitos saudáveis [1]. Neste 
contexto, jogos com intuitos distintos entre si são encontrados na literatura, destacando-se aqueles que: auxiliam em terapias, treinam profissionais, monitoram a saúde dos pacientes, educam, informam e promovem a saúde e o condicionamento físico.

No contexto dos serious games, o termo Abordagem de Comunicação refere-se a uma série de informações importantes na construção do jogo, dentre elas: conceituação artística, tipo de narrativa, roteiro, enredo, ambiente, interatividade, gênero do jogo, enredo e jogabilidade. Este artigo tem como objetivo apresentar a metodologia utilizada, com base na avaliação da Abordagem de Comunicação, no planejamento de um serious game voltado para mães, com intuito de apoiar os processos de ensino e de aprendizagem e informar sobre conceitos relacionados à saúde bucal de bebês. Esta metodologia foi desenvolvida devido à ausência de estudos relacionados a esse público-alvo e se destaca dos demais métodos ao permitir que o jogador opine sobre o tipo de Abordagem junto à equipe de desenvolvimento.

Para discutir a metodologia proposta, o presente trabalho faz uma breve explanação sobre a saúde bucal em bebês, englobando temas como políticas públicas de saúde atuais e problemáticas presentes nesta faixa etária, além de apresentar os serious games relacionados à Odontologia. Por fim, a metodologia é descrita e os resultados referentes à análise são apresentados.

\section{Saúde Bucal em Bebês}

O Ministério da Saúde tem se proposto a conduzir, a cada 10 anos, estudos para se identificar o quadro de saúde bucal de uma população ou determinado grupo populacional. O projeto SB Brasil foi concebido pelo Ministério da Saúde para diagnosticar as condições de saúde bucal da população brasileira e produziu um relatório, divulgado em 2004, que mostra que quase $27 \%$ das crianças entre 18 e 36 meses apresentam pelo menos um dente de leite com experiência de cárie dentária, proporção que chega a quase $60 \%$ em crianças de 5 anos de idade [9]. Os resultados apresentados pela pesquisa mostram que tal situação tende a piorar com o passar dos anos chegando a 70\% dos dentes cariados em crianças de até 12 anos e $90 \%$ em adolescentes de 15 a 19 anos. Tal quadro epidemiológico é agravado por fatores como: higienização bucal inadequada; consumo elevado de carboidratos fermentáveis; ausência de acompanhamento odontológico; falta de orientação adequada dos pais e responsáveis. Além disso, observa-se que a participação dos pais na promoção e manutenção das condições de saúde bucal dos seus filhos muitas vezes ocorre de forma tardia e compromete a dentição de leite da criança [10].

Diversas políticas educacionais atuam neste contexto com o objetivo de educar e informar aos pais sobre boas práticas e medidas de cuidados bucais em bebês. Porém, em relação aos cuidados com a saúde bucal, nota-se uma maior participação do sexo feminino no acompanhamento de seus filhos [11]. Diante desta realidade, a mãe surge como uma importante aliada na reprodução e disseminação das informações recebidas em campanhas e por meio de profissionais da saúde. Contudo, Corrêa [12] afirma que muitas delas não sabem lidar com a saúde bucal do seu bebê, pois têm medo de tocar a boca do seu filho e, por isso, 
tendem a negligenciar tais cuidados. As mães devem estar cientes de que os hábitos de higienização, estimulação e dieta, são indispensáveis para a boa saúde bucal do bebê os quais devem começar antes mesmo do nascimento. Para tanto, acompanhamentos de pré-natal e pós-parto devem ser realizados, como forma de repassar informações de prevenção às doenças bucais.

O trabalho de Magalhães et al. [13] ressalta que a Odontologia atual está inserida em um contexto preventivo, cujos objetivos se enquadram na promoção da qualidade de vida dos pacientes a partir de cuidados com a saúde bucal. Neste contexto, Cruz et al.[15] afirmam que a maioria dos programas brasileiros de conscientização em saúde bucal prioriza crianças entre 06 e 14 anos de idade, esquecendo muitas vezes o período de dentição de leite. Magalhães et al. [13] apontam cinco linhas de atuação preventivas nos programas de saúde voltados para promoção da saúde bucal em bebês, são elas: orientar a gestante, minimizar a transmissão de bactérias causadoras da cárie em bebês, orientar sobre a dieta alimentar, controlar mecanicamente o biofilme dentário e fazer uso do flúor em bebês.

Essas medidas geralmente são utilizadas de maneira isolada e por isso podem não resultar no objetivo esperado segundo esse mesmo estudo. Estas políticas demonstram que a informação/educação é sempre a primeira e mais eficiente linha de atuação.

\subsection{Novas Metodologias de Ação Preventiva}

$\mathrm{O}$ atendimento odontológico ao bebê tem como ponto central o enfoque preventivo para a manutenção da saúde e desenvolvimento saudável da criança. Atualmente os processos informativos e educacionais na Odontologia são feitos por meio de campanhas, panfletos, cartilhas e conversas diretas com os profissionais de saúde [20], sendo dependentes de ações em políticas públicas. A pesquisa de Oliveira [14], por exemplo, verificou no município de Campina Grande-PB um índice de 67,5\% de mães que não receberam nenhum tipo de informação sobre a saúde bucal do bebê. Essa carência de informações dos pais e responsáveis também é destaque nas pesquisas de Silveira et al. [28] e de Silva et al. [27], comprovando que a problemática está isenta de regionalizações e atinge todo o território brasileiro. Muitas causas podem ser citadas para a situação destacada, como: o número insuficiente de políticas públicas, despreparo de alguns profissionais de saúde e a falta de interesse das mães em executar as instruções passadas.

Com o intuito de melhorar as condições de saúde bucal e reduzir os riscos de doenças em crianças na primeira infância, um dos caminhos é a educação dos pais. Nesse cenário, o trabalho com as mães tem sido difundido dentro da Odontologia preventiva em bebês. Outra ferramenta que se destaca em campanhas educativas é a utilização de recursos multimídia para educar crianças e adultos. Neste contexto, os jogos computacionais na modalidade de serious games ganham destaque por possibilitar a definição de objetivos bem específicos. Estes surgem como uma alternativa adequada para disseminar informações e combater a insegurança das mães nos cuidados relacionados à saúde bucal do bebê. 


\section{Serious Games na Odontologia}

Na Odontologia, a simulação de procedimentos clínicos ainda representa maior parte das aplicações computacionais voltadas para a área [8]. Em contrapartida, nota-se uma presença crescente dos serious games na educação, informação e treinamento de pacientes e profissionais. No campo da saúde bucal, alguns jogos já abordam esta temática, principalmente envolvendo crianças como público-alvo. Porém, no campo da saúde bucal do bebê, um levantamento realizado por este trabalho apontou uma carência de iniciativas para orientar aos pais sobre os cuidados direcionados às crianças nesta faixa etária.

A utilização de serious games em treinamentos e simulações médicas apresentam, segundo pesquisas realizadas por Rosser et al.[16], as seguintes vantagens: baixo custo das plataformas de treinamento, ampla disponibilidade e portabilidade dos jogos, redução drástica no número de erros humanos e melhoria na execução de procedimentos específicos. Dentro dos serious games aplicados à Saúde, destacam-se os direcionados à Odontologia, pois a demanda crescente de ferramentas para estimular a tomada de decisão, treinamento, ensino e educação na área incentiva o desenvolvimento deste grupo de jogos.

Com o objetivo de verificar as técnicas utilizadas no planejamento de jogos direcionados à Odontologia, este trabalho realizou um levantamento de serious games relacionados a esta área existentes na literatura e no mercado de jogos. A metodologia utilizada neste levantamento deu-se em três etapas: pesquisa em bases de trabalhos científicos, seleção de jogos comerciais e de serious games apresentados em campanhas educativas. Ao longo da primeira etapa, os repositórios de trabalhos científicos pesquisados foram: IEEE Xplore, Science Direct, PubMed.gov Periódicos CAPES, Biblioteca on-line da SBC e Google Acadêmico. Por fim, esta fase contemplou a busca em 30 revistas (20 multidisciplinares e 10 computacionais) e 7 anais de congressos específicos de jogos, no período de 2005 a 2010 . As pesquisas foram realizadas por meio das buscas das seguintes palavras-chave nos repositórios destacados: health computer games, serious games, interactive computer games, computer games in dentistry, serious games in dentistry, jogos sérios, videogames na Odontologia, jogos computacionais na Odontologia, serious games na Odontologia e jogos na odontopediatria. Durante a segunda etapa do levantamento, a estratégia de pesquisa restringiu-se aos sítios na Internet de empresas relacionadas ao desenvolvimento de serious games e pesquisas em sítios de busca como Google e Bing. Por fim, a terceira etapa do levantamento abrange buscas de materiais educativos na forma de jogos computacionais desenvolvidos por empresas do ramo odontológico, destacando-se as empresas Colgate [17] e a Associação Americana de Odontologia [18].

Ao final da pesquisa foram selecionados 22 jogos relacionados à saúde bucal. Os jogos coletados passaram por um processo de teste e avaliação dos seguintes pontos: temática explorada, público-alvo, diferencial, distribuição da ferramenta e tipo de visualização. Inicialmente, três jogos foram descartados por não se enquadrar na modalidade de serious games, ou seja, estes jogos não relacionavam ou transmitiam informação específica ao jogador durante a interação. Por fim, os 19 serious games selecionados para 
análise foram: Dental Space Odyssey, Visit the dentist with marty, Tooth brush patch, Virtual Dental Implant Training Simulation (VDITS), PerioSim Force Feedback Dental Simulator (PerioSim), Dr. Rabbit, Trate os dentes, Foam works squirt, Forslund systems oral surgery simulator (FSOSS), Mouth power online, Dental office tree house, ToothPaste Tower, Smart Snack Orchard, Dental Defenders, Jogo da Escova, Pasta contra bactérias, Jogo dos Alimentos, Serious game para higiene bucal e To Tell the Tooth.

O gráfico 1 ilustra as características dos serious games selecionados durante a análise. As informações obtidas durante a avaliação preencheram uma tabela comparativa (exemplificada de forma resumida pela tabela 1 com os jogos que detinham maior rigor metodológico dentro da amostra analisada), após cada jogo ser testado, com base em aspectos pré-determinados, como: temática explorada, público-alvo, diferencial, distribuição da ferramenta e tipo de visualização. A partir disso, observou-se que as ferramentas existentes no mercado e na literatura se limitam a quatro temas principais: conceitos básicos de saúde bucal, higiene bucal de crianças e adultos, ida ao dentista e treinamento de profissionais. Outro fato interessante é o predomínio de dois grupos de público-alvo: estudantes de Odontologia e crianças. Em geral, os jogos voltados ao público infantil abordam conceitos relacionados à alimentação e higiene bucal, cuja característica marcante é a presença de elementos lúdicos para motivar os usuários e estimular o aprendizado. Neste contexto, destacam-se o Dental Space Odyssey [17] e o Tooth Brush Patch [18]. Ainda na linha de educação relacionada à higiene bucal se destaca a pesquisa em andamento de [19] para a construção de um serious game aplicado à saúde bucal, cuja meta é ajudar mães e filhos a obterem uma boa educação bucal a partir da utilização de um jogo baseado no uso de dispositivos de interação que proporcionarão maior imersão e interatividade no ambiente virtual.

Gráfico 1. Características dos serious games selecionados.

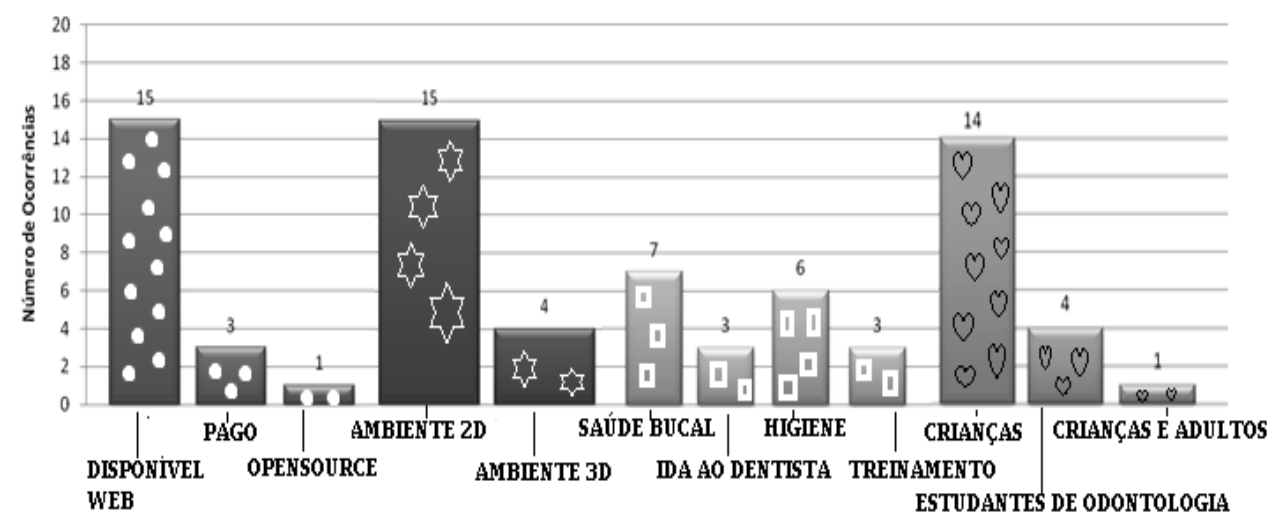

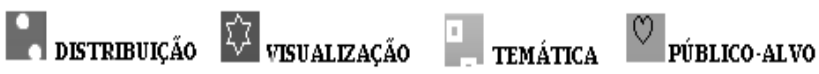

Tabela 1. Comparação de serious games para Odontologia 


\begin{tabular}{|c|c|c|c|c|c|}
\hline Serious games & Temática & $\begin{array}{c}\text { Público- } \\
\text { alvo }\end{array}$ & Diferencial & Distribuição & $\begin{array}{l}\text { Visua- } \\
\text { lização }\end{array}$ \\
\hline $\begin{array}{c}\text { Dental Space } \\
\text { Odyssey }\end{array}$ & $\begin{array}{c}\text { Conceitos } \\
\text { básicos de } \\
\text { saúde bucal. }\end{array}$ & $\begin{array}{c}\text { Crianças } \\
\text { (que saibam } \\
\text { ler) }\end{array}$ & $\begin{array}{l}\text { Utiliza um } \\
\text { roteiro lúdico } \\
\text { para ensinar } \\
\text { bons hábitos de } \\
\text { saúde bucal. }\end{array}$ & $\begin{array}{l}\text { Gratuito apenas } \\
\text { para jogar. } \\
\text { Disponível na } \\
\text { Web. }\end{array}$ & $2 \mathrm{D}$ \\
\hline $\begin{array}{c}\text { Visit the } \\
\text { Dentist With } \\
\text { Marty }\end{array}$ & Ida ao dentista. & Crianças. & $\begin{array}{c}\text { Traz a dinâmica } \\
\text { de uma história } \\
\text { interativa para } \\
\text { motivar o } \\
\text { jogador. } \\
\end{array}$ & $\begin{array}{l}\text { Gratuito apenas } \\
\text { para jogar. } \\
\text { Disponível na } \\
\text { Web. }\end{array}$ & $2 \mathrm{D}$ \\
\hline $\begin{array}{l}\text { Jogo da } \\
\text { Escova }\end{array}$ & $\begin{array}{c}\text { Conceitos } \\
\text { básicos de } \\
\text { higiene bucal. }\end{array}$ & $\begin{array}{l}\text { Crianças de } \\
6 \text { a } 8 \text { anos. }\end{array}$ & $\begin{array}{c}\text { Apresenta a } \\
\text { importância das } \\
\text { ferramentas } \\
\text { usadas durante a } \\
\text { higiene bucal } \\
\text { através de um } \\
\text { roteiro lúdico e } \\
\text { boa } \\
\text { jogabilidade. }\end{array}$ & $\begin{array}{l}\text { Gratuito apenas } \\
\text { para jogar. } \\
\text { Disponível na } \\
\text { Web. }\end{array}$ & $2 \mathrm{D}$ \\
\hline $\begin{array}{c}\text { Tooth Brush } \\
\text { Patch }\end{array}$ & $\begin{array}{c}\text { Conceitos } \\
\text { básicos de } \\
\text { higiene bucal. }\end{array}$ & $\begin{array}{l}\text { Crianças de } \\
2 \text { a } 4 \text { anos. }\end{array}$ & $\begin{array}{l}\text { Recursos de } \\
\text { áudio auxiliam } \\
\text { o aprendizado. }\end{array}$ & $\begin{array}{c}\text { Gratuito apenas } \\
\text { para jogar. } \\
\text { Disponível na } \\
\text { Web. } \\
\end{array}$ & $2 \mathrm{D}$ \\
\hline VDITS & $\begin{array}{l}\text { Treinamento } \\
\text { de } \\
\text { profissionais } \\
\text { (rotina de } \\
\text { trabalho) }\end{array}$ & $\begin{array}{c}\text { Profissional } \\
\text { de } \\
\text { Odontologia } \\
.\end{array}$ & $\begin{array}{l}\text { O realismo do } \\
\text { cenário e } \\
\text { Inteligência } \\
\text { Artificial } \\
\text { adotada torna o } \\
\text { jogo mais } \\
\text { realista e } \\
\text { estimula a } \\
\text { tomada de } \\
\text { decisão. }\end{array}$ & $\begin{array}{c}\text { Ferramenta } \\
\text { proprietária } \\
\text { (pago). }\end{array}$ & $3 \mathrm{D}$ \\
\hline PerioSim & $\begin{array}{l}\text { Treinamento } \\
\text { de } \\
\text { profissionais } \\
\text { (procedimento } \\
\text { s) }\end{array}$ & $\begin{array}{c}\text { Profissional } \\
\text { de } \\
\text { Odontologia } \\
\text {. }\end{array}$ & $\begin{array}{c}\text { Utiliza } \\
\text { dispositivo } \\
\text { háptico e } \\
\text { visualização 3D. }\end{array}$ & $\begin{array}{l}\text { Ferramenta } \\
\text { proprietária } \\
\text { (pago). }\end{array}$ & $3 \mathrm{D}$ \\
\hline FSOSS & $\begin{array}{l}\text { Treinamento } \\
\text { de } \\
\text { profissionais } \\
\text { (procedimento } \\
\text { s) }\end{array}$ & $\begin{array}{c}\text { Profissional } \\
\text { de } \\
\text { Odontologia } \\
.\end{array}$ & $\begin{array}{c}\text { Utiliza } \\
\text { dispositivo } \\
\text { háptico e } \\
\text { visualização 3D. }\end{array}$ & $\begin{array}{l}\text { Ferramenta } \\
\text { proprietária } \\
\text { (pago). }\end{array}$ & $3 \mathrm{D}$ \\
\hline
\end{tabular}


Dentre as aplicações analisadas, não foi encontrada menção às técnicas de planejamento. Entretanto, em algumas delas observou-se a presença de uma equipe multidisciplinar. A análise realizada ratificou que a temática saúde bucal dentro dos serious games está limitada ao público infantil e ao treinamento de profissionais. Apesar dos resultados positivos dos serious games na saúde, os conteúdos relacionados à saúde bucal do bebê ainda são repassados de forma tradicional às mães, por meio de campanhas, panfletos, cartilhas e conversas diretas com os profissionais de saúde. É seguindo esta premissa que este trabalho abordou a temática saúde bucal do bebê para mães.

\section{Serious Games Voltado Para Saúde Bucal em Bebês}

Ainda não há padrões definidos para o planejamento e desenvolvimento de um serious game voltado para saúde. Porém, alguns autores de serious games utilizam metodologias próprias em algumas etapas do planejamento e não avaliam as formas de apresentar narrativa, roteiro, cenário e desafios de maneira adequada ao público. Por exemplo, Kelly et. al. [22], baseiam-se em três elementos-chave para guiar o planejamento visual: conceituação artística (game design), integração e múltiplas escalas. Concomitantemente, Sliney et al. [23] propõem a construção de uma árvore hierárquica para nortear esse mesmo tipo de planejamento. Outra metodologia de destaque é a de Westera $e t$ al. [24] que sugere reduzir a complexidade dos serious games. Apesar de considerar a complexidade um elemento chave do jogo, esse trabalho define dois tipos de complexidade: planejada e emergente. Dentro da complexidade planejada existem níveis no quais esta pode ser reduzida: conceitual, prático e técnico. O nível conceitual envolve elementos relacionados à comunicação, colaboração e competição; o prático se refere ao feedback; por fim, o técnico que se refere à utilização de ferramentas para auxiliar desde a etapa de planejamento até a etapa de implementação em si.

Independente da metodologia e da área de conhecimento utilizada no serious game, dois fatores precisam ser definidos primordialmente em qualquer jogo: o público-alvo e o objetivo. Somente com estes dois pontos especificados é que se pode avançar para as próximas etapas do planejamento: o planejamento pedagógico, a escolha da metodologia, a definição do roteiro e a elaboração dos desafios. Neste trabalho, o serious game proposto tem como público-alvo mães e como objetivo auxiliá-las no processo de tomada de decisão em questões relacionadas à temática da saúde bucal do bebê. Para isto, o apoio de uma equipe multidisciplinar, formada por profissionais da Computação, Odontologia e Estatística, é essencial em todas as etapas de construção do serious game. Na fase de concepção do jogo, as discussões dentro da equipe multidisciplinar são fundamentais na definição dos aspectos relevantes às mães dentro da temática da saúde bucal do bebê, definindo os conteúdos pedagógicos utilizados e as necessidades de um estudo relacionado às Abordagens de Comunicação para adotar no jogo. Esta seção do artigo detalha as etapas anteriormente citadas. 


\subsection{Planejamento Pedagógico}

Os elementos pedagógicos são essenciais na construção de um serious game, pois norteiam a elaboração do roteiro, o planejamento dos desafios, a modelagem do cenário e a definição do gênero do jogo. O estudo temático se deu sob a orientação de odontologistas e participação da equipe multidisciplinar por meio de reuniões. Após esta etapa, organizou-se o tema em tópicos, que servem de base para a construção dos desafios e organização dos níveis de dificuldade. Os tópicos temáticos definidos e relacionados à saúde bucal do bebê são: aspectos relacionados à dieta alimentar, técnicas de higienização bucal em bebês, erupção dos dentes decíduos, fatores de riscos no desenvolvimento da cárie mamária e da cárie infantil, ida ao dentista, técnicas para apoiar os processos de ensino e aprendizagem voltadas a condutas adequadas de higiene bucal, doenças que a mãe pode transmitir ao seu filho através da boca e a importância da saúde bucal da mãe e do seu filho.

Ao se definir os tópicos temáticos, já podem ser esquematizados os níveis temáticos, também chamados de roteiros conceituais. A idéia foi organizar estes níveis de acordo com o desenvolvimento do bebê, ou seja, distribuir os temas de forma correlata à fase do bebê e às informações que a mãe precisa saber. Os níveis definidos podem ser vistos na figura 1 .

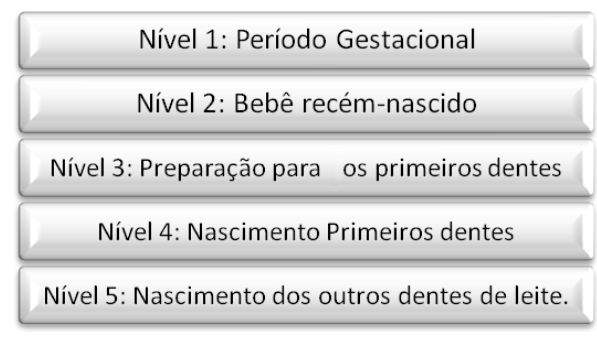

Figura 1. Roteiro conceitual do serious game para o ensino de conteúdos relacionados à saúde bucal de bebês.

\subsection{Abordagem de Comunicação}

Este trabalho utiliza-se da metodologia de planejamento dos serious games baseada na avaliação da Abordagem de Comunicação do jogo. Este termo, como citado no início deste artigo, influencia um conjunto de características do jogo, tais como: conceituação artística, tipo de narrativa, roteiro, enredo, ambiente, interatividade, gênero do jogo e jogabilidade. Todos estes elementos definem como o conteúdo pedagógico deve ser apresentado na tela e explorado pelo jogador. Esta análise é fundamental, pois o apelo de um serious game voltado para crianças é muito diferente de um direcionado a adultos [25]. Além disso, os programas preventivos precisam ser adequados a cada paciente e respectivamente aos pais, transmitidos de forma simples e eficiente e com motivação adequada para cada faixa etária [12]. 
$\mathrm{Na}$ literatura pesquisada, não foram encontrados trabalhos específicos que tratem a relação das mães e as abordagens dos jogos computacionais. Por esta razão, sentiu-se necessidade de avaliar diferentes Abordagens de Comunicação junto às mães para definir qual seria adotada no serious game deste trabalho. A avaliação das abordagens segue a seguinte estratégia de atuação:

1.Planejamento das Abordagens de Comunicação utilizadas na avaliação, com a equipe multidisciplinar.

2.Construção de storyboard dos protótipos das Abordagens de Comunicação.

3.Reunião com a equipe multidisciplinar e correção do storyboard.

4.Desenvolvimento dos protótipos.

5.Testes junto ao público-alvo.

6.Avaliação dos resultados.

Os storyboards são documentos que apresentam de forma simplificada a disposição dos elementos na tela do jogador, o roteiro e a sequência de cada cena (semelhantes a uma história em quadrinho). Esta estratégia em um projeto multidisciplinar ajuda na comunicação entre os membros da equipe e facilita a conversa entre os profissionais de áreas distintas neste tipo de projeto. Após uma segunda reunião com a equipe multidisciplinar, os storyboards são corrigidos e a fase de implementação dos protótipos de teste pode ser iniciada.

No contexto do desenvolvimento do serious game voltado para as mães no ensino de conteúdos relacionados à saúde bucal do bebê, optou-se pela elaboração de dois protótipos de teste: a abordagem formal e a abordagem lúdica. As abordagens diferem entre si por alguns aspectos: o grau de ludicidade, a construção da narrativa, os desafios, os cenários e o enredo. Por exemplo, na abordagem formal os elementos lúdicos devem ser dosados, a narrativa possui alguns termos técnicos em suas estruturas e o cenário e o enredo devem trazer elementos da rotina do jogador para o jogo. Enquanto na abordagem lúdica, o enredo é composto por elementos fantasiosos, a narrativa é repleta de elementos do enredo e a ludicidade é um elemento presente. A tabela 2 ilustra características pré-definidas em cada uma das abordagens.

Tabela 2. Características das Abordagens de Comunicação.

\begin{tabular}{|c|c|c|}
\hline Características & Abordagem Formal & Abordagem Lúdica \\
\hline Visão do jogador & Primeira pessoa & Primeira ou terceira pessoa \\
\hline Enredo & $\begin{array}{c}\text { Próxima à realidade, com } \\
\text { elementos cotidianos. }\end{array}$ & $\begin{array}{c}\text { Repleto de elementos fantasiosos } \\
\text { ou mágicos. Sai do cotidiano. }\end{array}$ \\
\hline Narrativa & $\begin{array}{c}\text { Remete-se diretamente ao } \\
\text { jogador e pode se utilizar de } \\
\text { conceitos técnicos. }\end{array}$ & $\begin{array}{c}\text { Utiliza elementos do enredo e } \\
\text { dirige-se aos personagens nas } \\
\text { mensagens. }\end{array}$ \\
\hline Objetivos & São claros e diretos. & Utiliza elementos do enredo. \\
\hline Desafios & Tentam propor desafios parecidos & Desafios são cheios de elementos \\
\hline
\end{tabular}




\begin{tabular}{|c|c|c|}
\hline & com os da realidade. & fantasiosos. \\
\hline Cenário & Podem ser ambientes 2D ou 3D. & Podem ser ambientes 2D ou 3D. \\
\hline
\end{tabular}

Com o intuito de avaliar a opinião do público-alvo, neste caso as mães, protótipos foram desenvolvidos com as duas Abordagens de Comunicação definidas. Estes protótipos foram implementados utilizando o motor gráfico Panda3D. Esta ferramenta foi utilizada por uma série de fatores: ser Open Source, ser compatível com a linguagem Python (para programação de funcionalidades não presentes no motor gráfico) e boa documentação de referência, dentre outros. Os protótipos foram definidos com o objetivo de captar as preferências do público-alvo, em relação a alguns aspectos do jogo 3D que estavam sob análise. Após as interações com os protótipos de cada Abordagem de Comunicação, a mãe responde a um formulário no formato de uma entrevista estruturada (roteiro prédeterminado). Os diários do entrevistador também foram analisados, os quais relatavam as impressões da entrevista e as situações não previstas em projeto.

A figura 2 apresenta as interfaces dos protótipos de Abordagem de Comunicação desenvolvidos. No protótipo Formal, o roteiro se baseou em um jogo de tabuleiro no qual a jogadora para vencê-lo deverá responder questões relacionadas à higiene bucal do seu bebê, podendo em alguns momentos também receber dicas sobre a temática explorada. O jogo desafia a mãe a chegar ao final do tabuleiro. Enquanto isso, no protótipo Lúdico elaborou-se um roteiro e uma narrativa repletos de elementos divertidos sem perder o embasamento teórico que subsidia o serious game. Neste protótipo o roteiro adotado foi o seguinte: em um reino muito distante havia um rei e uma rainha que acabaram de ter uma filha, cujo nascimento foi amaldiçoado pelo bruxo Tártaro; caso a princesa tenha algum problema dental, todos do reino ficarão com os sorrisos tristes e os dentes podres. Para que isto não aconteça, a mãe é motivada a ajudar o rei e a rainha a evitar que tal maldição se concretize.

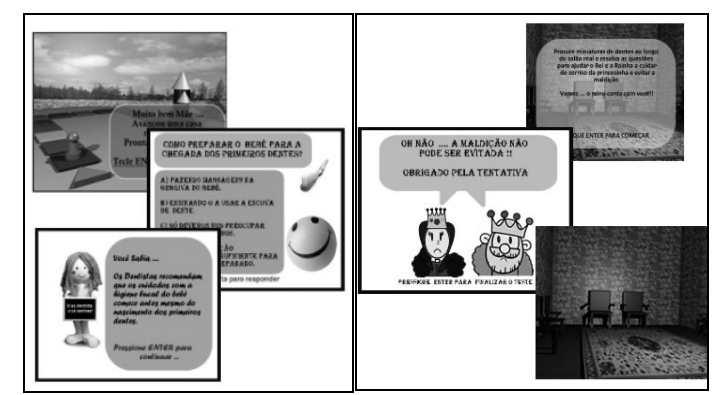

Figura 2. Interface da Abordagem de Comunicação Formal e da Lúdica, respectivamente. 


\section{Resultados Preliminares}

Este projeto foi aprovado pelo Comitê de Ética em Pesquisa com Seres Humanos (CEP) do Hospital Universitário Lauro Wanderley (HULW) na UFPB, Protocolo no 167/09 e FR: 285463. A coleta de dados, referente aos testes, foi realizada na Clínica de Odontopediatria e na Clínica Integrada Infantil, pertencentes à Universidade Federal da Paraíba. A amostra voluntária utilizada na pesquisa foi composta por um grupo de 20 mães atendidas pelas clínicas citadas, não sendo incluídas na amostra aquelas que relatassem ser analfabetas devido ao fato de existirem mensagens textuais ao longo das interações com os protótipos, sendo necessária a compreensão do usuário. A figura 3 registra um desses testes.

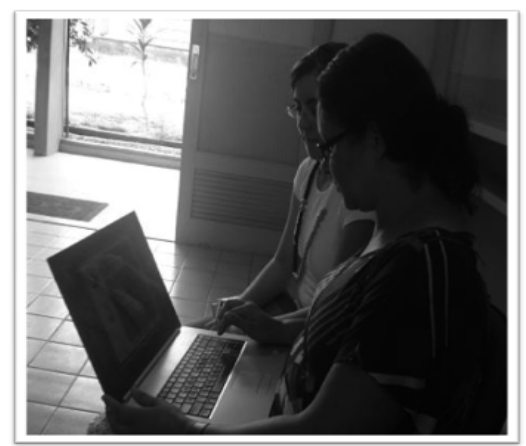

Figura 3. Aplicação dos testes.

Diversas técnicas poderiam ter sido utilizadas durante a coleta de informações, como questionários, formulários e diários do entrevistador. Os diários do entrevistador são anotações realizadas ao longo do dia pelo mesmo se referindo a situações, frases ou até mesmo observações de um dia de campo. Concomitantemente, os formulários e questionários são compostos por questões predefinidas e direcionadas ao público-alvo. O que difere os dois métodos é a aplicação da técnica, pois os questionários são respondidos pelos próprios entrevistados contrapondo os formulários que necessitam do papel do entrevistador para repassar as perguntas. Neste trabalho, optou-se pelo uso da técnica dos formulários para adequar o discurso das perguntas às mães, visto que, este público-alvo é muito amplo e diversificado.

$\mathrm{Na}$ análise da Abordagem de Comunicação, as mães interagiram com os dois protótipos de teste e, após isto, responderam a um formulário elaborado especificamente para o teste, sob a forma de uma enquete. O formulário era composto por quatro grupos de perguntas relacionadas com: a relação da mãe com o dentista, o perfil socioeconômico, os conhecimentos gerais sobre a temática e a impressão da mãe sobre os jogos testados.

A faixa etária predominante na amostra foi de mães acima de 38 anos, correspondendo a $60 \%$ das entrevistadas. Outra informação relevante é que $65 \%$ das mães referiram não ter conhecimento de informática, contudo tal limitação não afetou o 
desempenho e a motivação das mesmas durante os jogos. De maneira geral, as mães consideraram interessante a idéia de fazer um jogo voltado para elas sobre esta temática. A sua importância ficou muito clara ao se encontrar uma realidade em que mais de $80 \%$ das mães entrevistadas não receberam nenhum tipo de orientação relacionada à higiene bucal do bebê. Neste grupo de mães, encontraram-se casos de algumas que levaram seus filhos para tratar cárie precoce da infância, decorrente de uma higiene bucal incorreta na fase de bebê. Informações equivocadas sobre higienização bucal, associada à ingestão de alimentos cariogênicos na fase de bebê, foram comprovadas nesta amostra.

As distinções entre as abordagens foram notadas pelas mães ao longo das interações. Porém, as diferenças mais relevantes, segundo as mães, estavam nas narrativas. Tal fato pode ser comprovado pelo entendimento das mensagens por parte das mães nas duas abordagens. Cerca de $90 \%$ das mães relataram ser muito fácil compreender as mensagens e os discursos na Abordagem Lúdica, contrapondo 85\% da Abordagem Formal. Os diários do entrevistador registraram que as mães ficavam mais atentas às questões na Abordagem Lúdica e elas normalmente tinham um desempenho melhor nessa abordagem, devido ao maior envolvimento causado pelo enredo e o roteiro.

Ao avaliar o elemento motivação nas duas Abordagens, notou-se uma pequena diferença entre as mesmas. Na Lúdica, as mães que declararam sentir algum tipo de motivação atingiram $90 \%$ das entrevistadas, destas $35 \%$ afirmavam estar muito motivadas, contrapondo $95 \%$ da Formal, com 30\% muito motivadas. Porém os diários do entrevistador relataram que as mães demonstravam maior vontade de terminar a Abordagem Lúdica, pois queriam "salvar a princesinha".

Outro critério avaliado neste trabalho foi a nota atribuída pelas mães a cada uma das abordagens. As notas foram emitidas dentro de uma escala de 1 a 5 . Ao final da etapa de testes, o protótipo lúdico conseguiu a nota média de 4.6 contrapondo os 4.4 obtidos pelo protótipo formal. Novamente a Abordagem Lúdica teve um desempenho melhor do que a formal.

\section{Considerações Finais}

Aliar informações sobre Odontologia com a dinâmica dos jogos é uma boa alternativa, pois diversas pesquisas comprovam o aprendizado efetivo neste tipo de ambiente diante de fins educacionais e de treinamento [21][26]. Este trabalho ressalta a importância da colaboração entre os profissionais da Odontologia e Computação para a construção de um serious game, voltado às mães, abordando temas relacionados à saúde bucal de bebês. Para isto foi apresentada uma metodologia de planejamento de jogo no contexto de uma equipe multidisciplinar. Essa metodologia foi baseada na avaliação das Abordagens de Comunicação com o público-alvo. Tal estudo fez-se necessário, pois não foi encontrada na literatura pesquisas envolvendo as mães no planejamento de serious games. Após o término da análise dos dados, a versão final do jogo irá adotar a Abordagem de Comunicação escolhida pelo público-alvo. 
Com relação à impressão relacionada às abordagens, a pesquisa sugeriu que a Abordagem Lúdica e a Abordagem Formal motivaram as mães de forma semelhante. Entretanto, no aspecto envolvimento, a Lúdica se destacou da Formal. As mães, em geral, sentiram-se mais estimuladas a finalizar o protótipo Lúdico, apesar de terem apontado um fácil entendimento das mensagens e do cenário virtual para ambos os protótipos. Outro dado interessante é que $60 \%$ das mães se sentiram motivadas igualmente pelos protótipos, dando nota máxima indiferente do conhecimento em informática.

Apesar das sutis diferenças entre as Abordagens de Comunicação nos aspectos analisados, este trabalho definiu que o serious game direcionado à saúde bucal em bebês adotará a Abordagem de Comunicação Lúdica, por uma série de fatores entre eles:

1. Maior envolvimento das mães durante o jogo, fato que aumentava a atenção da mãe durante as jogadas (de acordo com os diários do entrevistador);

2. Nota média maior do que a Abordagem Formal, refletindo uma preferência pela Abordagem Lúdica;

3. As narrativas, o enredo e o cenário desta abordagem foram apontados como elementos que facilitaram a compreensão do conteúdo explorado.

O serious game proposto foi finalizado e os testes finais estão em fase de execução. Estes testes avaliarão as opiniões finais das mães.

\section{Agradecimentos}

Os autores agradecem às mães que participaram de forma voluntária da etapa de testes com as Abordagens de Comunicação, colaborando com a evolução do trabalho, e à CAPES por financiar o projeto.

\section{Referências}

[1] Machado, L.S., Moraes, R.M., Nunes, F. (2009) Serious games para Saúde e Treinamento Imersivo. Book Chapter. In: Fátima L. S. Nunes; Liliane S. Machado; Márcio S. Pinho; Cláudio Kirner. (Org.). Abordagens Práticas de Realidade Virtual e Aumentada. Porto Alegre: SBC. 2009, 31-60.

[2] Thompson, D., Baranowski, T., Buday, R., Baranowski, J., Thompson, V., Jago, R., et al. (2008) Serious Video Games for Health: How Behavioral Science Guided the Development of a Serious Video Game. Simulation \& Gaming. 2008.

[3] Gunter, G.A., Kenny R.F., Vick, E.H. (2008) Taking educational games seriously: using the RETAIN model to design endogenous fantasy into standalone educational games. Educational Technology Research and Development. 56(5-6):511-537. 
[4] Papastergio, M. (2009) Exploring the potential of computer and video games for health and physical education: A literature review. Computers \& Education. 53(3):603-622.

[5] Elverdam, C., Aarseth, E. (2007) Game Classification and Game Design. Games and Culture. 2(1):3-22.

[6] Derryberry, A. (2007) Serious games: online games for learning. Adobe Systems. White Paper: Adobe Press. Acessado em: Janeiro de 2010. Disponível em: www.adobe.com/.../elearning/.../serious_games_wp.pdf

[7] Wong, W.L. et al. (2007) Serious Video Game Effectiveness. ACM International Conference Proceeding Series; 203:49-55.

[8] Jasinevicius, T.R. et al. (2004) An Evaluation of Two Dental Simulation Systems: VR versus Contemporary Non-Computer-Assisted. J Dent Educ. 68(11): 1151-1162.

[9] Queiroz, R. C. de S et al. (2009) Pesquisa sobre as Condições de Saúde Bucal da População Brasileira (SB Brasil 2003): seus dados não produzem estimativas populacionais, mas há possibilidade de correção. Cad. Saúde Pública, vol.25, n.1.

[10] Alves, M., Volschan, B., Haas, N. (2004) Educação em saúde bucal: sensibilização dos pais de crianças atendidas na clínica integrada de duas universidades privadas. Pesquisa Brasileira de Odontopediatria e Clínica Integrada. 4(1): 47-51.

[11] Silva, D. D. F. et al. (2008) Cuidados em saúde bucal na primeira infância: percepções e conhecimentos de pais ou responsáveis de crianças em um centro de saúde de Porto Alegre, RS. Rev. Odonto Ciênc. 23(4):375-379

[12] Corrêa, M.S.N.P.; Dissenha, R.M.S.; Welffort, S.Y.K. (2005) Saúde Bucal do bebê ao adolescente. Guia de orientação para as gestantes, pais, profissionais da saúde e educadores. Editora Santos.

[13] Magalhães, A.C., Rios, D., Honório, H.M., Machado, M.A.A.M. (2009) Estratégias educativas-preventivas para a promoção de saúde bucal na primeira infância. Odontologia clínica-científica. 8(3):245-249. Jul/Set. 2009.

[14] Oliveira, V.B. de (2007) Jogos de regras e a resolução de problemas. Editora Vozes. ISBN: 978-85-326-3080-3. 3 $3^{\text {a }}$ edição. Petrópolis-RJ. 2007.

[15] Cruz, A.A.G. et al. (2004) Percepção materna sobre higiene bucal de bebês: Um estudo no Hospital Alcides Carneiro. Campina Grande-PB. Pesquisa Brasileira Odontopediatria Clínica Integrada. 4(3):185-189, set./dez.2004

[16] Rosser J.C.Jr, Lynch P.J., Haskamp L.A., Yalif A., Gentile D.A., Giammaria L.(2004) Are Video Game Players Better at Laparoscopic Surgery? Presentation at the Medicine Meets Virtual Reality Conference, Newport Beach, CA. 2004.

[17] Colgate. Acessado em: Março de 2010. Disponível em: http://www.colgate.com.br. 
[18] American Dental Association (ADA). Disponível em: Www.ada.org/public/games/games.asp. Acessado em: Dezembro de 2009.

[19] Rodrigues, H.F., Machado, L.S., Valença, A.M.G. (2009) Uma Proposta de Serious game Aplicado à Educação e Saúde Bucal. In: Anais do Workshop de Realidade Virtual e Aumentada, Santos, Brazil. CDROM. 2009

[20] Machado, M.A.A.M., Silva, S.M.B., Abdo, R.C.C.(2005) Odontologia em bebês protocolos clínicos, preventivos e restauradores, Santos. 1.ed. 2005.

[21] Johnsen, K., Raij, A., Stevens, A., Lind, D.S., Lok, B.(2007) The validity of a virtual human experience for interpersonal skills education. Proceedings SIGCHI Conf. on Human Factors in Computing Systems (CHI '07). ACM. 2007. 1049-1058.

[22] Kelly. H. et al (2007) How to Build Serious games. Communications of the ACM. 50(7).

[23] Sliney, A., Murphy, D., Phelan, D. (2008). Evaluation of home based junior doctor medical simulator. SimuTools.

[24] Westera, W., Nadolski, R.J., Hummel, H.G.K. and Wopereis, I.G.J.H. (2008) Serious games for higher education: a framework for reducing design complexity. Journal of Computer Assisted Learning. 24(5):420-432. 2008.

[25] Zyda, M. (2005) From Visual Simulation to Virtual Reality to Games, no. 9. In: IEEEComputer Society, pp. 2532.

[26] Kebritchi, M., Hirumi, A. (2008) Examining the pedagogical foundations of modern educational computer games. Computers \& Education. 51(04):1729-1743, Dezembro, 2008.

[27] Silva, D.D.F. et al. (2008) Cuidados em saúde bucal na primeira infância: percepções e conhecimentos de pais ou responsáveis de crianças em um centro de saúde de Porto Alegre, RS. Rev. odonto ciência; 23(4):375-379, Outubro-Dezembro, 2008.

[28] Siqueira, D. et al. (2009) Avaliação do interesse dos pais pela saúde bucal de seus filhos pelo índice de comparecimento às consultas odontológicas de crianças em idade pré-escolar. ConScientiae Saúde. 8(2):239-244. Junho 2009. 